\title{
O Mercado de Streaming na Coreia do Sul: Disputas Internas e a Invasão Estrangeira
}

\author{
Daniela Mazur \\ Doutoranda e Mestre em Comunicação \\ no Programa de Pós-Graduação da \\ Universidade Federal Fluminense (UFF) \\ e Bacharel em Estudos de Mídia pela \\ mesma Universidade. Coordenadora \\ do projeto Série Clube (UFF), \\ dedicado ao estudo da ficção seriada \\ televisiva. Pesquisadora associada ao \\ MidiÁsia (UFF) e ao TeleVisões (UFF). \\ E-mail: danielamazur@id.uff.br.
}

\section{Melina Meimaridis}

Doutora e Mestre em Comunicação no Programa de Pós-Graduação da Universidade Federal Fluminense (UFF) e graduada em Estudos de Mídia pela mesma Universidade. Pesquisadora associada ao TeleVisões (UFF) e ao projeto Série Clube (UFF).

E-mail: melmaridis@hotmail.com.

\section{Daniel Rios}

Doutorando e Mestre em Comunicação no Programa de Pós-Graduação da Universidade Federal Fluminense (UFF) e Bacharel em Estudos de Mídia pela mesma Universidade. Pesquisador associado ao TeleVisões (UFF) e ao projeto Série Clube (UFF).

E-mail: daniel_rios@id.uff.br.
Resumo: Através da Hallyu, a Coreia do Sul tem se tornado um polo significativo de produção de cultura pop. Devido às particularidades do mercado de TV e internet no país, as empresas de streaming estrangeiras têm tido dificuldade para crescerem lá. Em contrapartida, a Coreia se estabeleceu como um dos maiores mercados nacionais de streaming de vídeo na Ásia. A partir de uma revisão da literatura e de matérias jornalísticas, identificamos dois fenômenos significativos. Primeiro, um grupo de conglomerados locais se juntaram para formar a plataforma Wavve com o objetivo de enfrentar o "mal estrangeiro", representado pela presença da Netflix no país. Segundo, a indústria sulcoreana está se utilizando da influência global das plataformas estrangeiras para expandir o alcance da Hallyu. Este estudo de caso, então, revela nuances e estratégias de uma indústria de mídia em ascensão na periferia global.

Palavras-chave: Hallyu, Coreia de Sul, streaming, Wavve.

\section{El Mercado de Streaming en Corea del Sur: Disputas Internas e Invasión Extranjera}

Resumen: A partir de Hallyu, Corea del Sur se convierte en un importante centro de producción de la cultura pop. Debido a las particularidades del mercado de televisión e internet de ese país, las empresas de streaming extranjeras tienen dificultades para crecer ahí. Por otra parte, Corea del Sur es uno de los mayores mercados nacionales de streaming de vídeo en Asia. Basándose en una revisión de la literatura y en artículos periodísticos, identificamos dos fenómenos significativos. Primero, un grupo de conglomerados locales se unió para formar la plataforma Wavve con el objetivo de enfrentar el "mal extranjero" representado por la presencia de Netflix en el país. Segundo, la industria surcoreana está utilizando la influencia global de plataformas extranjeras para ampliar el alcance de la Hallyu. Este estudio de caso apunta los matices y las estrategias de una industria mediática en ascenso en la periferia global.

Palabras clave: Hallyu, Corea del Sur, streaming, Wavve.

The Streaming Market in South Korea: Internal Disputes and the Foreign Invasion

Abstract: South Korea has become a significant center for the production of pop culture through Hallyu. Due to the particularities of the TV and internet market in the country, foreign streaming companies have struggled to grow. In contrast, Korea has established itself as one of the largest national video streaming markets in Asia. From a review of the literature and journalistic articles, we identified two significant phenomena happening in the country: first, to face the "foreign evil" represented by Netflix, a group of local conglomerates came together to form the Wavve platform; and second, the Korean industry is taking advantage of the global influence of foreign platforms to expand Hallyu's reach. This case study reveals the nuances and strategies of a rising media industry in the global periphery.

Keywords: Hallyu, South Korea, streaming, Wavve. 
O cenário do streaming na Coreia do Sul esquentou nos últimos anos com a chegada de novos agentes. A Coreia, hoje, é um dos maiores mercados consumidores de streaming de vídeo na Ásia (Gupta, 2019), alimentado especialmente pela alta inserção nacional das tecnologias de vídeo e da internet banda larga (Kim et al., 2017). O país possui infraestrutura tecnológica altamente desenvolvida, cenário local de streaming bem arquitetado, $100 \%$ de penetração da TV a cabo nas casas sul-coreanas e pacotes baratos de canais por assinatura e de internet (Buckthought, 2020; Park, 2018). Em vista disso, a chegada da Netflix no país em 2016 foi hostil. A imprensa aponta palavras de confronto para descrever o cenário, como indicam as manchetes de notícias a seguir, de tradução nossa: "Guerra de streamings de vídeo esquenta na Coreia do Sul" (https://bit. ly/3wNdtzo), "Emissoras sul-coreanas se unem contra a Netflix com um novo serviço de streaming" (https://bit.ly/3gWPt6c) e "Serviços de vídeo online da Coreia do Sul enfrentam batalha difícil contra a Netflix" (https://bit.ly/3zRVnOD). Esses veículos midiáticos, dessa maneira, apresentam uma narrativa que coloca a empresa de streaming estadunidense como o "perigo estrangeiro".

A televisão leste-asiática é considerada atualmente como um verdadeiro fenômeno global (Kim, 2014). A Coreia do Sul é a décima segunda maior economia do mundo e detentora da Hallyu (Onda Coreana), o grande fenômeno transnacional da cultura pop sul-coreana. Os lucros de exportação com a Hallyu ultrapassaram pela primeira vez em 2019 a marca de 10 bilhões de dólares e, em 2020, o governo sul-coreano designou 1,42 bilhão de dólares em incentivos para continuar apoiando a criação de conteúdo cultural local (Jun, 2020) em favor do crescimento dessa influência pelo mundo. É por meio da Hallyu que o país está movimentando seu mercado interno e apresentando uma imagem atualizada da nação para o resto do mundo, especialmente através do audiovisual. Por isso, a fim de manter o controle da narrativa nacional e assegurar os lucros com sua produção de conteúdo, movimentações internas estão acontecendo em favor de fortalecer e proteger o mercado local de streaming das forças estrangeiras.

A chegada da Netflix ao país não ocorreu sem esforços, uma vez que os mercados nacionais de televisão e streaming já eram bem estruturados. Contudo, o crescimento da plataforma nos últimos dois anos é inegável, com a adequação da empresa às demandas locais. Tal crescimento acelerado assusta agentes locais, em vista do reconhecimento da força global dessa plataforma. Além disso, o mercado de streaming como um todo está em destaque no mundo em razão da pandemia de Covid-19, que manteve diferentes países em isolamento social e aumentou em $51 \%$ o consumo global de serviços de streaming de vídeo (Jun, 2020), o que compõe um cenário de grande interesse sul-coreano. A própria Coreia do Sul tornou-se uma peça essencial nesse momento, uma vez que, diferentemente de outros países, sua produção de entretenimento audiovisual basicamente não parou devido à pandemia, graças ao desempenho do governo frente à crise de saúde pública, que regulamentou e monitorou as produções (Tai, 2020). Tal fato tornou essa indústria fundamental para alimentar diversas plataformas de streaming pelo mundo, assim como a própria Netflix, nesse momento de crise.

Nesse sentido, a guerra de streamings na Coreia do Sul acontece em meio a diferentes estratégias locais e estrangeiras. A partir da abordagem do imperialismo de plataforma (Jin, 2015), revisão de literatura atualizada e análise de matérias jornalísticas locais, o presente artigo se propõe a entender esse mercado e os entraves que atualmente acontecem nele. Investigamos como a indústria de entretenimento sul-coreana tem lidado com o avanço da plataforma estrangeira no território nacional e examinamos as estratégias do país frente a essa expansão. Argumentamos que ocorreram dois fenômenos distintos no país. Primeiro, os conglomerados de mídia local se uniram para formar a Wavve, uma plataforma de streaming nacional, que tem o objetivo de enfrentar o "perigo estrangeiro" que a Netflix representa para o mercado. Segundo, a indústria sul-coreana está transformando o alcance das plataformas estrangeiras em um instrumento para expandir a Hallyu globalmente. Portanto, é uma estratégia de mão dupla, na qual a indústria nacional se utiliza da Netflix para atingir públicos estrangeiros, mas localmente é hostil à empresa. 


\section{A ascensão da televisão sul-coreana}

A indústria televisiva sul-coreana se desenvolveu em meio ao cenário do avanço acelerado da economia do país e de grandes transformações na sociedade. Os primeiros aparelhos de televisão chegaram à Coreia do Sul em 1956, no pósguerra. Contudo, foi apenas no início dos anos 1960, com o levante da ditadura

${ }^{1} \mathrm{~A}$ Coreia do Sul passou por um período de ditadura militar que se estendeu oficialmente entre 1961 e 1987, enquanto o país ainda se reestruturava em seu pós-guerra e se compreendia como uma nova nação depois da divisão do território peninsular. Esse período foi marcado por intensa censura, limitada liberdade de expressão, planos de aceleração econômica e ataques violentos àqueles que se rebelavam contra o regime. $O$ fim do regime em 1987 não foi concreto em mudanças democráticas no país, já que o regime ditatorial ainda influenciava o cenário político. O processo de democratização se estendeu pelos anos seguintes e apenas no fim dos anos 1990 mudanças concretas nesse aspecto foram colocadas em prática (Hwang, 2010).

\footnotetext{
${ }^{2}$ A Crise Financeira Asiática de 1997 espalhou-se por grande parte do Sudeste e Leste Asiático e atingiu em cheio a Coreia do Sul, desestabilizando a economia do país que estava em processo de aceleramento desde os
} modelos desenvolvimentistas da ditadura (Hwang, 2010). Dois fatores contribuíram para desencadear especificamente a crise na indústria sul-coreana: o uso de financiamento externo para compensar os prejuízos e continuar o processo de expansão dos negócios, além da queda no sentimento de transparência com o aumento de escândalos de corrupção (Jang \& Paik, 2012). Com isso, os bancos nacionais acabaram com uma dívida externa impossível de pagar, o que levou à falência inúmeras empresas e ao aumento da taxa de desempregados. Todavia, a longo prazo, a crise foi um dos principais impulsionadores da reestruturação do setor financeiro e das estratégias utilizadas pela indústria sulcoreana (Mazur, 2018). militar $^{1}$, que a televisão foi devidamente regulamentada no país, já que o governo ditatorial idealizava a rápida modernização da nação, progresso do qual a TV era um símbolo. Foi nessa década que o formato Drama de TV foi importado do Japão e começou a ser produzido regularmente no país, entretanto, a produção nacional ainda era limitada devido à pouca infraestrutura e à censura em voga, que regulava vigorosamente a mídia. Na época, as grades de programação eram preenchidas por meio da importação de produtos estrangeiros, majoritariamente estadunidenses (Lee, 2004).

A entrada expressiva de conteúdo estrangeiro representou um momento de trocas culturais, mas, especialmente, de preocupação com a preservação da cultura local. Incentivou-se, assim, a produção de programas televisivos para suprir a demanda interna de modo a diminuir a dependência dessas importações. Em razão das medidas protecionistas governamentais e da gradual estruturação televisiva nacional, a partir da década de 1980, o apelo da televisão sul-coreana começou a crescer entre o público local e, consequentemente, esse mercado se tornou menos dependente da importação de programação televisiva (Y. Kim, 2019). Esse protecionismo se repetia nos países vizinhos, que também enxergavam os influxos ocidentais como uma ameaça. Por essa razão, davam preferência ao consumo de produtos culturais da região, porque eles se mostravam mais "inofensivos" por dialogarem com questões identitárias compartilhadas no cenário do leste asiático, reafirmando valores locais. Além disso, tal "ameaça estrangeira" também se tornou um incentivo para o desenvolvimento das indústrias culturais nacionais, em favor da produção de seus próprios conteúdos midiáticos, estruturando indústrias que hoje alimentam os mercados locais e comercializam produtos entre si, criando, assim, novas lógicas regionais no âmbito cultural.

A década de 1990 foi essencial para a compreensão da cultura como um setor econômico em potencial para o desenvolvimento da Coreia do Sul. O governo de Kim Youngsam (1993-1997) despertou a concepção da indústria cultural como parte de um plano de estratégia econômica nacional, o que foi mantido e expandido pelos governantes posteriores. Além de decretar leis a fim de atrair investimentos na indústria cinematográfica (Jang \& Paik, 2012; Shim, 2006), também requereu apoio financeiro dos conglomerados empresariais, os chaebols, para desenvolver o setor local. Então, o cenário que estava começando a se formar pela liberdade vivenciada com a transição democrática, a entrada de capital privado nas emissoras e a introdução da televisão a cabo no país criou um ambiente mais plural para a televisão nacional (Nam, 2008; S. Shim, 2008). Ainda nessa década, a emissora SBS foi fundada, arquitetando-se, assim, o que hoje é conhecido como "Big Three", os três maiores canais da TV aberta sul-coreana: KBS, MBC e SBS. Com isso, a demanda por dramas de TV aumentou significativamente, tornando esse gênero a maior fonte de lucro da indústria televisiva e um dos maiores potenciais de exportação cultural da Coreia do Sul à época (Ju, 2017). E, após a Crise Financeira Asiática de $1997^{2}$, o país enxergou na reestruturação de sua indústria cultural uma estratégia com potencial de renovação econômica. A instabilidade financeira da época possibilitou a implementação da tática de redução de preço de seus produtos televisivos, colocando-os abaixo da média do mercado regional e atraindo importadores (D. Shim, 2008).

A China foi a primeira grande importadora da produção de entretenimento sulcoreano e parte essencial para o desenvolvimento da cultura pop da Coreia do Sul como um fenômeno transnacional (Joo, 2011; Shim, 2006). Esse consumo inicial ocorreu especialmente porque os dramas de TV sul-coreanos, mesmo estrangeiros, dialogavam com a cultura chinesa, então, eram vistos pelo governo chinês como uma alternativa mais segura do que os conteúdos ocidentais. Esse diálogo cultural se repetiu com outros países da região, razão pela qual o conceito de Proximidade Cultural (Straubhaar, 1991) é relevante para entender a circulação dos produtos sulcoreanos nesse mercado. Essa região compartilha um fluxo cultural construído por 
séculos de trocas, interlocuções e intervenções devido à cercania geográfica, aos fluxos migratórios e a atos político-diplomáticos. Tal fluxo perpassa genericamente esses países, criando certo sentimento de proximidade e familiaridade entre os públicos consumidores, um imaginário generalista de uma "identidade leste-asiática". Desse modo, as audiências leste-asiáticas apresentam-se receptivas a produtos próximos culturalmente (Keane et al., 2007), desenvolvendo interconexões culturais entre essas nações e facilitando o fluxo regional do mercado audiovisual.

Hoje, a Coreia do Sul simboliza, em meio aos fluxos internacionais, um centro pulsante de tendências e formatos de sucesso, que se expande regional e globalmente. Esse fenômeno cultural é chamado de Hallyu (Onda Coreana), que abarca o fluxo de produtos e influências culturais originários da Coreia do Sul que estão alcançando diferentes públicos pelo mundo (Hanaki et al., 2007; Shim, 2006). A produção televisiva do país é essencial para entender as lutas de poder construídas dentro e fora da Ásia em favor da cultura pop e da identidade contemporânea nacional, além de ser o primeiro termômetro do potencial sul-coreano como produtor e exportador global de cultura.

Assim, mesmo em uma posição ainda desfavorável frente à força ocidental e globalizante dos Estados Unidos, a Coreia do Sul trava desafios à hegemonia midiática ostentada pelo país anglófono. Mazur, Meimaridis e Albuquerque (2019), por exemplo, argumentam que a Coreia do Sul se utiliza de sua influência televisiva regional e do potencial da indústria local para adaptar narrativas estadunidenses aos paradigmas ficcionais televisivos nacionais e, consequentemente, regionais, em vista de sua forte presença no mercado leste-asiático. Dessa forma, o país peninsular tenciona a dominância estadunidense, uma vez que a autoridade legitimadora passa dos Estados Unidos para a Coreia do Sul, já que o poder de adaptar uma narrativa à realidade local significa definir-se como o centro de uma nova ordem estabelecida (Mazur et al., 2019, p. 92).

As narrativas televisivas sul-coreanas são intensos instrumentos de poder e, de fato, a demanda por produtos da indústria cultural sul-coreana vem crescendo também fora da Ásia, como na América Latina (Min et al., 2018), na África (Kim, 2017) e na Europa (Sung, 2014). Em especial, destacamos a popularidade das produções sulcoreanas no próprio contexto brasileiro (Mazur, 2018; Urbano, 2020). Tal demanda levou emissoras sul-coreanas, como MBC e SBS, a lançarem seus próprios canais no Youtube com parte do seu conteúdo legendado em diferentes idiomas. Esforços como esse se dão em favor de maximizar o alcance da Hallyu pelo mundo. Em 2019, a Coreia do Sul lucrou 12.3 bilhões de dólares apenas com a exportação de produtos culturais, um aumento de $22.4 \%$ em comparação ao ano anterior (Yonhap News Agency, 2020a). Por isso, o mercado de streaming é um espaço de grande disputa, com problemáticas que podem ser observadas não apenas na Coreia do Sul, mas também em outras potências do Leste Asiático.

\section{Tendências no mercado de streaming do Leste da Ásia}

O Leste Asiático atualmente se posiciona como uma importante região no cenário mundial, onde vários países se destacam, tanto pelo rápido progresso econômico nas últimas décadas quanto pela consolidação de suas indústrias midiáticas nacionais. Japão e Coreia do Sul se configuram como efervescentes polos de produção, distribuição e consumo de programas televisivos: os animes japoneses e os dramas sul-coreanos são produtos de exportação a nível global (Chua \& Iwabuchi, 2008; Kim, 2014). Mas, se antes a circulação de conteúdo audiovisual era feita exclusivamente pelas redes de televisão tradicional, seja ela via radiodifusão ou satélite, cada vez mais observa-se o papel da internet nesse processo (Wee, 2016, p. 209). Nesse sentido, na última década o desenvolvimento de plataformas de distribuição digital tem complexificado o fluxo de programação televisiva da região.

Sem dúvida, o Leste da Ásia é um território extremamente heterogêneo, tendo em vista que é constituído por uma grande pluralidade de países e culturas. Contudo, identificamos duas tendências que nos permitem ilustrar a paisagem atual do mercado de streaming na região. Por um lado, há iniciativas nacionais de criação de plataformas, muitas vezes capitaneadas por conglomerados midiáticos pré- 
${ }^{3}$ Baidu é a empresa que controla a principal plataforma de pesquisa online da China. Atualmente, a plataforma chinesa é a segunda maior ferramenta de pesquisa online do mundo, perdendo apenas para a estadunidense Google (Curtin \& Li, 2018). estabelecidos. Ao mesmo tempo, há também a inserção de plataformas estrangeiras, especialmente as estadunidenses Netflix e Amazon Prime Video, que têm como objetivo abocanhar o mercado da região. Essas duas tendências guardam muitas semelhanças com casos registrados em outras regiões periféricas, como a América Latina (Meimaridis, Mazur, \& Rios, 2020; Rios \& Scarlata, 2018).

Por exemplo, podemos observar a força da gigante iQiyi na China. Comandada pela Baidu ${ }^{3}$, a plataforma de streaming é, desde 2013, o principal serviço de vídeo sob demanda da China (Curtin \& Li, 2018). O modelo de negócios é centrado na lógica do conteúdo freemium: há a opção de utilizar o serviço gratuitamente mediante a visualização de anúncios, e a de pagar uma taxa de assinatura que livra o usuário da publicidade. A iQiyi oferece conteúdo variado, com produções chinesas e estrangeiras, tanto de países asiáticos, como de países ocidentais. Além disso, assim como a Netflix, a iQiyi também produz conteúdos originais para a plataforma. Em 2020, a plataforma chinesa contratou o antigo vice-presidente de políticas públicas da Netflix Ásia-Pacífico, Kuek Yu-Chuang, para ser seu vice-presidente de negócios internacionais. A contratação faz parte da atual estratégia de expansão da iQiyi pela região do Sudeste Asiático (Frater, 2019a). Curtin e Li (2018) argumentam que um dos principais públicos-alvo da iQiyi são os jovens, tendo em vista que estão cada vez mais se distanciando da programação televisiva tradicional e buscando o consumo de vídeos no meio digital, principalmente pelos smartphones.

Já no caso do Japão, observamos um cenário tomado pelo sentimento de cautela com a chegada da Netflix no país. De acordo com Tse (2020), desde que a empresa estadunidense iniciou suas atividades no território japonês, em meados de 2015, a indústria midiática local passou a chamar a plataforma de "black ship" (kurofune). O termo é derivado de uma expedição militar estadunidense ocorrida na segunda metade do século XIX que forçou o Japão a abrir sua economia para o mundo ocidental depois de passar duzentos anos em reclusão. Atualmente, a analogia do "black ship" tem sido "usada pelo público para descrever o lançamento de um produto, serviço ou empresa ocidental (geralmente estadunidense), assim como seu impacto no mercado interno" (Tse, 2020, p. 144, tradução nossa). Ainda que contenha uma carga negativa, a utilização do termo pela mídia japonesa muitas vezes se apresenta ambivalente: ao mesmo tempo que a empresa ameaça a indústria local, também representa a diversificação de conteúdo para a audiência nacional.

\section{0 "mal estrangeiro"}

A Coreia do Sul também é um mercado valioso para a Netflix, não apenas pelos novos assinantes em potencial, como também pela possibilidade de exportação de conteúdos locais. Segundo Greg Peters, diretor de streaming e parcerias, "a Coreia é um mercado incrível de criação e consumo de conteúdo" (Lee, 2016, tradução nossa), o que demonstra que a empresa está interessada não apenas em vender seu serviço no mercado sul-coreano, mas também em ser proprietária de "conteúdos sul-coreanos" e exportá-los para outras regiões. Então, como parte da expansão à Ásia, a Netflix chegou ao território sul-coreano em janeiro de 2016. A plataforma adentrou o mercado de forma tímida, conquistando apenas $300 \mathrm{mil}$ assinaturas até o final de 2017, mas, rapidamente, em fevereiro de 2019, chegou ao número de 2.4 milhões e no primeiro semestre de 2020 já somava 3.28 milhões de assinantes (Yang, 2020).

Desde o início, a empresa procurou surfar na Onda Coreana: em 2017, a primeira tentativa foi o longa-metragem Okja (2017), dirigido pelo reconhecido cineasta Bong Joon-ho, que teve investimento de pouco mais de 48 milhões de dólares e resultou no aumento de 70 mil assinantes sul-coreanos para 200 mil após o lançamento do filme na plataforma (Kim \& Oh, 2020). Apesar desse sucesso, a Netflix manteve baixo desempenho na Coreia do Sul nos dois primeiros anos de atividade no país (Gupta, 2019; Kim \& Oh, 2020). Um dos grandes trunfos da Netflix no mundo, a espectatorialidade por meio de dispositivos móveis (Daidj \& Egert, 2018), já não era novidade para os sul-coreanos: parte do conteúdo televisivo no país já era produzido com intuito de ser consumido também através de smartphones. 
Além disso, quando a plataforma estadunidense chegou à Coreia do Sul, encontrou o mercado de streaming já fortalecido e com grandes nomes do cenário local. A plataforma de streaming POOQ, por exemplo, já estava em atuação desde 2011. Formada a partir de um empreendimento conjunto controlado pelas três maiores emissoras abertas do país, $\mathrm{KBS}, \mathrm{MBC}$ e SBS, a POOQ era voltada especialmente a catch-up $T V$, transmitindo canais sul-coreanos, além de seu catálogo de filmes e dramas de TV. Ademais, a empresa de telecomunicações SK Broadband lançou em 2016 a Oksusu. A plataforma nasceu da fusão entre a Btv e a Hoppin, serviços de streaming também controlados pela SK Broadband. Assim como a POOQ, a Oksusu também oferecia uma combinação entre serviços de vídeo sob demanda e transmissão linear de canais disponíveis no país, com destaque para aqueles relacionados a campeonatos esportivos (Kim, 2016). As plataformas POOQ e Oksusu se consolidaram no mercado local e até 2019 davam conta da grande maioria do consumo de streaming nacional, quando a primeira tinha dez milhões de assinantes e a segunda, quatro milhões (H. Kim, 2019).

Ainda que a TV a cabo possua 100\% de penetração no país; que em 2019 mais de 33 milhões de sul-coreanos fossem assinantes desse serviço (numa população de 51 milhões, atualmente) (Buckthought, 2020); e que o país tenha demonstrado a força de sua TV aberta, o mercado de streaming de vídeo sul-coreano está em crescimento acelerado. Em 2016, os sul-coreanos gastavam anualmente a média por usuário de 97 dólares em serviços de assinatura, enquanto no Japão a média era de 103 e na China, 31. As previsões locais, já em 2017, apontavam para um grande avanço no setor, antecipando que até 2021 a indústria do streaming no país triplicaria os números de 2016, quando valia 142 milhões de dólares (Cher, 2017). Contudo, na realidade, esse crescimento foi ainda superior: em 2020, o mercado de streaming de vídeo na Coreia do Sul foi estimado em aproximadamente 658 milhões de dólares (Chae, 2020).

Esse cenário foi atrativo para a Netflix, um interesse alimentado também pela necessidade de mediação ao resto do mercado leste-asiático, uma vez que a empresa estadunidense falhou em adentrar o mercado chinês, o maior em potencial consumidor do mundo atualmente e um mediador importante na região. O governo chinês impõe medidas restritivas às empresas estrangeiras que pretendem entrar no mercado a fim de salvaguardar a economia e cultura local, empecilhos em razão dos quais a Netflix desistiu da empreitada (Riley, 2016). O interessante é que a Coreia do Sul, hoje, encontra-se em um cenário previsto pela China, em que o "perigo estrangeiro" se manifesta e intimida o mercado local, então algumas medidas tardias estão sendo tomadas pelo governo e indústria sul-coreanos.

Se inicialmente a Netflix encontrou certa resistência da audiência sul-coreana, atualmente a situação parece estar se revertendo. Entre 2018 e 2019, o número de assinaturas da plataforma estadunidense quadruplicou, atingindo 1,86 milhões na Coreia do Sul (Lee \& Lee, 2019). Para além de disponibilizar conteúdos estrangeiros que não eram exibidos na televisão sul-coreana e comprar licenciamento de programas locais, a empresa também passou a investir em produções e coproduções locais, como Busted! (2018-presente), Love Alarm (2019-2021) e Kingdom (2019-presente). Também recorreu a planos mais acessíveis específicos para smartphones, em vista da grande inserção desse tipo de dispositivo no país.

Ao que tudo parece, a expansão da Netflix na Coreia do Sul é motivada também pelo sucesso da Hallyu, a fim de chegar em países onde esse fenômeno tem entrada mais facilitada do que a empresa estadunidense, especialmente nações do Leste e Sudeste Asiáticos, uma vez que é percebido que a indústria estadunidense tem falhado em se manter relevante em mercados com forte tradição em conteúdo televisivo local e regional (Keane et al., 2007). Portanto, as produções sul-coreanas se tornam veículos atrativos para a conquista de assinantes em novas partes do mundo, além de serem oportunidades de aproveitamento de um consumo de nicho em ascensão no mundo, como é o caso da Onda Coreana.

Com o crescimento da Netflix na Coreia, a indústria de entretenimento local ficou dividida quanto a como se posicionar. As maiores emissoras nacionais se recusaram a licenciar seu conteúdo mais recente para a Netflix. De acordo com 
a Korean Broadcasters Association, uma aliança com a Netflix seria o "ponto de partida da destruição da indústria midiática" (Seo, 2018). Alternativamente, os canais fechados e produtoras, como a Studio Dragon, continuaram vendendo seus produtos para a empresa, com o argumento de que a Hallyu poderia ser abalada caso não acontecessem parcerias da indústria cultural sul-coreana com o Youtube, a própria Netflix e outras plataformas de OTT (Seo, 2018). "Se o governo sul-coreano não é capaz de bloquear a Netflix e o YouTube como o governo chinês fez, vender conteúdo para a Netflix pode ser uma forma de comercializar produtos midiáticos", argumentou um executivo da One TV (Seo, 2018, tradução nossa). O embate tratase, na realidade, de uma disputa entre interesses econômicos locais e globais, na qual a Coreia do Sul ainda depende da Netflix para adentrar os fluxos audiovisuais globais, mas, ao mesmo tempo, deseja proteger seu mercado doméstico.

Mesmo nesse cenário conturbado, a Netflix parece não oscilar e continua investindo em conteúdo local a fim de manter seu crescimento no país e alimentar a demanda de produtos da Hallyu em âmbito global. No final de 2019, a Netflix assinou uma aliança com a maior provedora de conteúdo da Coreia do Sul, a CJ ENM, e a JTBC Content Hub para a produção de conteúdo pelos próximos anos. A empresa estadunidense também adquiriu recentemente uma participação de 4,99\% no Studio Dragon e um contrato de exclusividade com a LG U+. E o investimento da Netflix em conteúdo coreano deve continuar a aumentar. De acordo com Ted Sarandos, diretor de conteúdo da Netflix, "como o mundo gosta tanto do conteúdo sul-coreano, faremos um grande investimento na Coreia como parte importante da expansão asiática" (Kim \& Oh, 2020). Para a Netflix, é importante garantir os direitos de propriedade intelectual por meio de investimento em custos de produção, porque a plataforma precisa que o conteúdo seja continuamente distribuído. Se apenas os direitos de transmissão forem garantidos, haverá restrições ao uso do conteúdo a médio e longo prazo, então a empresa tem apostado incessantemente nessas produções, especialmente as estratégicas. As produções sul-coreanas, por exemplo, abrem entrada para o mercado regional e dialogam com o cenário global. "Mais da metade das horas de conteúdo asiático assistidas na Netflix este ano são vistas fora da região, então temos confiança de que nossa próxima lista de produções asiáticas encontrará fãs em seus países e no exterior", apontou Sarandos (Lui, 2018, tradução nossa).

\section{A reação sul-coreana}

A principal reação à expansão da Netflix e outras empresas estadunidenses em mercados locais tem sido por meio de propostas de regulamentação das plataformas de streaming. No caso da Coreia do Sul e de outros países da periferia global, como Brasil e México, essa questão se torna particularmente relevante, tendo em vista as assimetrias existentes nas indústrias audiovisuais locais (Baladron \& Rivero, 2019). Além das comprovações históricas dos impactos do imperialismo cultural e da globalização pelo mundo, a preocupação governamental e mercadológica da Coreia do Sul frente às forças estrangeiras possui raízes também no que Jin (2015) descreve como Imperialismo de Plataforma.

Tal fenômeno representa um novo tipo de imperialismo, que continua concentrando capital e reafirmando o lugar de domínio do Ocidente, especialmente dos Estados Unidos, nos jogos de poder no cenário global. Em razão dos Estados Unidos continuarem afirmando seu poder por meio, também, das plataformas online (Facebook, Google, Apple, Netflix, entre outras), o Imperialismo de Plataforma evidencia o papel das corporações transnacionais, especialmente as estadunidenses, que comungam de privilégios nas relações de poder com países não-ocidentais (Jin, 2015, p. 50) e de trocas tecnológicas e fluxos de capital desiguais, implicando, assim, a contínua dominância desse cenário. No Imperialismo de Plataforma, as formas de dominação desses países de fora do eixo central pelos Estados Unidos são diferentes, porque a propriedade intelectual e os valores comerciais estão embutidos em plataformas, de maneiras mais efetivas para a acumulação de capital e expansão de poder (Jin, 2015, p. 12), potencializando, assim, as assimetrias e a manutenção da hegemonia.

A preocupação em proteger as conquistas locais em um cenário global hostil aos agentes não-ocidentais evidencia a necessidade de medidas regulatórias para 
conter o avanço globalizante no ambiente nacional e regional. A indústria sulcoreana apresentou em 2020 novas restrições, como a proposta de "Taxa de uso da rede" ("Network usage fee", tradução nossa). Com ela, os fornecedores de acesso à internet (Internet Service Providers, ISPs) acusam os provedores de conteúdo estrangeiros, como a Netflix, de "pegarem carona" ("free riders", tradução nossa) e os pressionam a pagar taxas extras, já que esses serviços estão aumentando o tráfego de internet (Yang, 2020). A Netflix deve pagar a taxa para que seu serviço de streaming possa ser fornecido aos usuários locais com qualidade de transmissão.

Também em 2020, a Assembleia Nacional da Coreia do Sul aprovou o projeto de lei apelidado de "Lei Netflix", exigindo que ISPs e provedores de conteúdo se responsabilizem por manter a qualidade do serviço de rede. A empresa estadunidense alegou, em ação civil, que não pode pagar essas taxas e que os ISPs domésticos não têm o direito de as impor. Contudo, além disso, a Comissão de Comércio Justo do governo da Coreia do Sul também sinalizou que seria mais rígida nas avaliações de empresas estrangeiras de OTT e demandou à Netflix alterações nos termos de uso que são considerados injustos, como as mudanças em planos e preços sem o consentimento do consumidor (Shim, 2020). Oficiais estadunidenses do Departamento de Estado dos EUA interferiram, alegando preocupações de que as regras visavam injustamente as plataformas estrangeiras (Shim, 2020).

Por outro lado, a estrutura do "nacionalismo pop" também é útil para entender o caso sul-coreano. O termo foi introduzido por Joo (2011) apontando para o surgimento de discursos nacionalistas em países que alcançaram sucesso exportando seus produtos culturais, gerando certo orgulho nacional para o povo. $\mathrm{O}$ autor foi diretamente inspirado pelo trabalho de Iwabuchi (2001) sobre "trans/nacionalismo", em que percebeu os vieses nacionalistas nos discursos dos japoneses ao abordar as exportações de conteúdo de cultura pop para o resto do mundo (Joo, 2011). Devido ao alcance e popularidade da Hallyu, o nacionalismo pop também é uma questão importante no mercado de streaming sul-coreano, transformando a paisagem coreana em uma disputa ainda mais complexa.

De fato, o nacionalismo pop influenciou as estratégias da Coreia do Sul para impedir o avanço da Netflix no país. Diferentemente de outros países periféricos onde o mercado local conta com diversas empresas disputando a atenção do público, como é no caso do Brasil (Meimaridis et al., 2020) e do México (Cornelio-Marí, 2017), a decisão geral da indústria do entretenimento sul-coreana se concentrou em outra solução: fundir as duas maiores empresas nativas de streaming do país, POOQ e Oksusu, em uma única plataforma, a Wavve.

\section{O surgimento da Wavve}

A Wavve é uma joint venture entre a gigante das telecomunicações SK Telecom e as emissoras abertas KBS, MBC e SBS. O CEO da SK Telecom chamou o novo serviço de "Netflix da Ásia" e apontou planos de expansão no Sudeste Asiático, com foco na produção de conteúdo original a ser vendido no exterior (Doyle, 2019). A Wavve estreou em setembro de 2019 com aproximadamente 14 milhões de assinantes herdados da fusão. No entanto, nem todos os assinantes são clientes pagantes, uma vez que a Comissão de Comércio Justo somente aprovou a fusão com a condição de que as três emissoras não começassem a cobrar pelo conteúdo que já forneciam gratuitamente. Também firmou parcerias com outras plataformas asiáticas, como ViuTV (Hong Kong), iflix (Malásia) e iQiyi (China). A empresa tem interesse em expandir o potencial da televisão sul-coreana e streaming nos mercados asiáticos e globais. O governo nacional apoiou a fusão entre a Oksusu e a POOQ a favor da criação da Wavve com base em estratégias de proteção do mercado nacional. Essa estratégia não é nova, já que o mecanismo de busca local Naver foi e é exitoso em impedir que o Google domine o mercado sul-coreano, ao tornar o seu conteúdo exclusivo indecifrável ao rastreio da ferramenta estadunidense (Doyle, 2019).

A Wavve se comprometeu não apenas a defender o mercado nacional da Netflix e do YouTube, mas também a avançar no exterior, competindo globalmente por meio da produção de conteúdo original. A empresa, assim, visa conquistar públicos locais e regionais. A plataforma vai investir mais de $\mathbf{2 5 0}$ milhões de dólares para produzir 

${ }^{4}$ Valores aproximados segundo a tabela de
conversão de won sul-coreano para o real
brasileiro em 27 de setembro de 2020. conteúdo exclusivo até 2023 (Chae, 2020), além de fornecer serviços de mídia com tecnologias locais de realidade virtual e aumentada (Frater, 2019b). Somado a isso, a indústria cultural coreana também investiu, por meio da Wavve, em acordos com plataformas internacionais para continuar expandindo a influência do conteúdo televisivo e cinematográfico da Hallyu pelo mundo. Recentemente, a Wavve fechou acordo com a plataforma estadunidense NBCUniversal para a exportação de conteúdo original (Kim, 2020). Além disso, as cinco maiores emissoras e conglomerados sul-coreanos (SBS, KBS, MBC, JTBC e CJ ENM) também trabalham diretamente com a plataforma honconguesa ViuTV, que assegura mais de $90 \%$ do conteúdo sul-coreano para o seu público (Lim, 2020).

Durante seu lançamento, a Wavve teve como objetivo acumular 5 milhões de assinantes pagantes e vendas anuais de 500 bilhões de won (cerca de 2 bilhões de reais) até 2023. A assinatura da Wavve disponibilizaria mais de mil títulos, incluindo filmes e dramas de TV nacionais e internacionais. No entanto, um ano após a estreia da Wavve, o desempenho da plataforma não foi tão positivo quanto o esperado. A Wavve iniciou seus serviços em setembro de 2019 oferecendo três planos de streaming, Basic, Standard e Premium, custando aproximadamente de $R \$ 37,00$ a $R \$ 65,00$ reais por mês. Esses preços são mais acessíveis do que os da Netflix, que variam entre $R \$ 44,50$ e $R \$ 68,00$ reais $^{4}$. Nos primeiros meses, a plataforma sulcoreana conseguiu se manter na liderança, conforme o esperado com a herança de assinantes de POOQ e Oksusu (Yonhap News Agency, 2020b). O sucesso, entretanto, foi prejudicado inicialmente pela pouca diversidade de conteúdo do catálogo, pela dificuldade de acesso aos canais a cabo por meio da plataforma e pela instabilidade na qualidade de vídeo do serviço (KoreaTechToday, 2019). O número de usuários ativos mensais do streaming local diminuiu no final de 2019 , enquanto o da Netflix disparou, consolidando seu lugar no topo.

Em dezembro de 2019, a Netflix ultrapassou a Wavve, tornando-se a plataforma mais popular da Coreia do Sul. O sucesso recente da Netflix nesse mercado alimentou a guerra de streamings, com a Wavve investindo ainda mais em conteúdo original, especialmente visando os fãs da Hallyu. O mais recente é o primeiro reality show do grupo de K-pop SuperM, intitulado de "M-topia". O programa é uma parceria da plataforma com a maior e mais antiga empresa de K-pop, a SM Entertainment. O SuperM é um grupo com estratégia de expansão global, já que é fruto de uma parceria com a Capitol Records, prestigiosa gravadora estadunidense. Além disso, o grupo é formado por grandes nomes de grupos da SM de sucesso, que participam do projeto paralelamente aos seus grupos originais. Os ídolos do K-pop Taemin, do grupo Shinee, Baekhyun e Kai, do EXO, Ten e Lucas, do WayV e Taeyong e Mark, do NCT 127, fazem parte do grupo especial, que estreou com seu primeiro álbum no topo da lista Billboard 200, tornando-se o segundo grupo de K-pop da história a liderar essa parada musical dos Estados Unidos. Porém, a Netflix está tentando se familiarizar o mais rápido possível também com esse potencial de venda: o primeiro documentário da plataforma estadunidense sobre um grupo de K-pop foi lançado em outubro de 2020 e abordou um grupo também de massivo sucesso global: o BlackPink (Lee, 2020), grupo de K-pop com o videoclipe mais visto do Youtube atualmente e o ato feminino sul-coreano de maior sucesso na Billboard Hot 100 (Rolli, 2020).

O potencial de diálogo com conteúdo atraente no mercado local, regional e global da Hallyu pode ser a arma essencial para o real crescimento da Wavve, uma vez que a Netflix ainda não está completamente familiarizada com as particularidades do fenômeno. Por outro lado, o fato de a Wavve estar investindo principalmente no mercado interno e em parcerias com plataformas de streaming estrangeiras para vender direitos de licenciamento é um movimento estratégico, considerando o potencial existente para as produções culturais sul-coreanas. O plano da Wavve é produzir "dois terços do conteúdo coreano de apelo comercial suficiente para viajar para o exterior" (Doyle, 2019), enquanto tenta avaliar e desafiar a força avassaladora das empresas estrangeiras de streaming no país.

Concomitantemente, enquanto o Globoplay no Brasil busca se consolidar no mercado local e a mexicana Blim tenta conquistar o mercado latino-americano, a sul-coreana Wavve apresenta ambições tanto locais quanto globais. Só o tempo dirá qual estratégia funcionará melhor, dando retorno lucrativo para essas empresas. 
Por ora, destacamos o fato de que, em vários outros países da periferia global, conglomerados de mídia local estão buscando estratégias para se manterem relevantes em um momento em que, cada vez mais, a experiência de consumo televisivo se encontra fragmentada e desterritorializada.

A Coreia do Sul, parte essencial do que conhecemos hoje como periferia global, apresenta-se como um dos países com maior destaque de soft power (Nye, 2004) no cenário internacional. Um de seus instrumentos mais eficazes de influência moderada é a cultura. Atualmente, a periferia global busca espaço e diálogo, a fim de alimentar sua força contra o centro. Por isso, a luta nas guerras de streamings é extremamente significativa para o Leste Asiático e, principalmente, para a Coreia do Sul, por ser este o maior nome em poder brando da região. Essas plataformas apresentam-se como espaços eficazes de disponibilização e divulgação de conteúdos nacionais. Plataformas locais e periféricas como a sul-coreana Wavve, a chinesa iQiyi, e a brasileira Globoplay são espaços não só para o escoamento de produtos estrangeiros, mas também para a criação e distribuição de produções locais, que contribuem para o fortalecimento da resistência periférica global em meio ao ambiente internacional que ainda valoriza as empresas e o conteúdo estadunidense.

\section{Considerações finais}

O fenômeno da Hallyu ainda está crescendo globalmente e permanece vinculado a um nicho de consumo de usuários que acessam produtos culturais pela internet. A Coreia do Sul está conseguindo exportar um estilo de vida, uma identidade atualizada do que significa ser sul-coreano, por meio dos diversos aspectos culturais que compõem a Onda Coreana. A presença, em particular, de dramas de TV em canais ocidentais e plataformas de streaming, está expandindo o potencial transnacional da televisão sul-coreana, que, apesar de suas limitações idiomáticas e culturais, está lentamente ganhando espaço no cotidiano ocidental e se tornando parte vigente da dinâmica dos fluxos televisivos globais.

Pesquisadores interessados em analisar a chegada e a consolidação da Netflix no mercado sul-coreano precisam ser cautelosos. A empresa de streaming é uma oportunidade e uma ameaça ao país. Por causa disso, a Coreia é hostil e cautelosa no mercado local, mas vê a Netflix e outras plataformas de streaming estrangeiras como uma forma essencial de continuar a expandir a Hallyu para mercados fora da Ásia. Diante do Imperialismo de Plataforma realizado pelos Estados Unidos por meio dessas empresas transnacionais, a indústria do entretenimento sulcoreano tenta se defender e sobreviver, mesmo com os avanços estrangeiros em seu território. Contudo, na tentativa de conquistar mais espaço no cenário internacional, o país aposta nessas próprias plataformas estrangeiras. $O$ estudo de caso da Wavve apresentado neste artigo chama a atenção porque revela os esforços de um país oriental e periférico em meio aos fluxos globais ao lidar com os avanços das plataformas ocidentais e centrais em seu país. Embora a Wavve esteja em seus estágios iniciais, a plataforma já nos mostra como o campo de batalha do streaming na Coreia do Sul está esquentando rapidamente, apontando para estratégias atualizadas para sobreviver a novos tipos de imperialismo. A Coreia do Sul, dessa forma, desponta cada vez mais no cenário dos fluxos televisivos globais e revela-se um importante e complexo agente da periferia global em ascensão.

\section{Referências}

Baladron, M., \& Rivero, E. (2019). Video-on-demand services in Latin America: Trends and challenges towards access, concentration and regulation. Journal of Digital Media \& Policy, 10(1), 109-126. https://doi.org/10.1386/jdmp.10.1.109_1

Buckthought, J. (2020). The Asia Video Report 2020. Asia Video Industry Association. https://avia.org/wp-content/uploads/_pda/2019/11/The-Asia-Video-IndustryReport-2020.pdf 
Chae, Y.-H. (2020, 8 de junho). Homegrown OTT players to take on Netflix with new original content. Yonhap News Agency. https://en.yna.co.kr/view/AEN 20200708003400320 ?section=search\&fbclid=IwAROxgbddDHV-cwW9duVM_ YX7AtGuhOd7iFCEYW_-2wr39488Haykph7M9os

Cher, B. (2017, 8 de junho). South Korea's paid-for video market to triple by 2021. The Drum. https://www.thedrum.com/news/2017/06/08/south-korea-s-paidvideo-market-triple-2021

Chua, B. H., \& Iwabuchi, K. (2008). East Asian Pop Culture: Analyzing the Korean Wave. Hong Kong University Press.

Cornelio-Marí, E. M. (2017). Digital delivery in Mexico: A global newcomer stirs the local giants. In C. Barker, \& M. Wiatrowski (Eds.), The Age of Netflix: Critical essays on streaming media, digital delivery and instant access (pp. 201-228). McFarland \& Company.

Curtin, M., \& Li, Y. (2018). iQiyi: China's Internet Tigers Take Television. In D. Johnson (Org.), From Networks to Netflix (pp. 343-353). Routledge.

Daidj, N., \& Egert, C. (2018). Towards new coopetition-based business models? The case of Netflix on the French market. Journal of Research in Marketing and Entrepreneurship, 20(1), 99-120. https://doi.org/10.1108/JRME-11-2016-0049

Doyle, J. (2019, 14 de janeiro). 'Netflix of Asia' to take on US streaming giants like YouTube as Korea's Oksusu and Pooq team up. South China Morning Post. https://www.scmp.com/week-asia/economics/article/2181578/screen-grab-koreanbroadcasters-join-forces-fight-netflix

Frater, P. (2019a, 10 de junho). China's iQIYI Hires Netflix Executive Kuek Yu-Chuang For Asia Expansion Role. Variety. https://variety.com/2020/biz/asia/china-iqiyinetflix-kuek-yu-chuang-asia-1234631191

Frater, P. (2019b, 21 de agosto). Korean Regulators Approve Four-Way Streaming Merger. Variety. https://variety.com/2019/digital/asia/korean-regulators-approvefour-way-streaming-merger-1203308973/

Gupta, R. (2019, 5 de setembro). Netflix cuts price to attract subscribers in South Korea. Market Realist. https://marketrealist.com/2019/09/netflix-cuts-price-toattract-subscribers-in-south-korea/

Hanaki, T., Singhal, A., Han, M. W., Kim, D. K., \& Chitnis, K. (2007). Hanryu sweeps East Asia: How winter sonata is gripping Japan. International Communication Gazette, 69(3), 281-294. https://doi.org/10.1177/1748048507076581

Hwang, K. M. (2010). A history of Korea. Macmillan International Higher Education.

Iwabuchi, K. (2001). Uses of Japanese popular culture: Trans/nationalism and postcolonial desire for 'Asia'. Emergences: Journal for the Study of Media \& Composite Cultures, 11(2), 199-222. https://doi.org/10.1080/10457220120098955

Jang, G., \& Paik, W. K. (2012). Korean Wave as tool for Korea's new cultural diplomacy. Advances in Applied Sociology, 2(3), 196-202. https://doi.org/10.4236/ aasoci.2012.23026

Jin, D. Y. (2015). Digital platforms, imperialism and political culture. Routledge.

Joo, J. (2011). Transnationalization of Korean popular culture and the rise of "pop nationalism" in Korea. The Journal of Popular Culture, 44(3), 489-504. https://doi. org/10.1111/j.1540-5931.2011.00845.x

Ju, H. (2017). National television moves to the region and beyond: South Korean TV drama production with a new cultural act. Journal of International Communication, 23(1), 94-114. https://doi.org/10.1080/13216597.2017.1291443 
Jun, B. (2020, 17 de junho). Korean Wave Hallyu Brings Cultural Power, Tech Influence. INDVSTRVS. https://indvstrvs.com/korean-wave-hallyu-brings-culturalpower-tech-influence

Keane, M., Fung, A. Y. H., \& Moran, A. (2007). New television, globalization, and the East Asian cultural imagination. Hong Kong University Press.

Kim, B.-W. (2020, 12 de abril). Streaming platform Wavve partners with NBCUniversal to export Korean content. The Korea Herald. http://www.koreaherald.com/view. php?ud=20200412000158\&fbclid=IwAR3bOwsJK5ZxWftXmJkeVfXYEcPgM9I_4jeR MsJB1uixLU7_bWAQnKOPu\%200

Kim, H.J. (2019, 16 de setembro). (LEAD) Homegrown S. Korean OTT platform to launch this week. Yonhap News Agency. https://en.yna.co.kr/view/AEN201909160052513 20\#: :text=SEOUL\%2C\%20Sept.,providing\%20the\%20service\%20said\%20Monday

Kim, J. (2014). Reading Asian Television Drama: Crossing Borders and Breaking Boundaries. Ib Tauris.

Kim, M. S., Kim, E., Hwang, S. Y., Kim, J., \& Kim, S. (2017). Willingness to pay for overthe-top services in China and Korea. Telecommunications Policy, 41(3), 197-207. https://doi.org/10.1016/j.telpol.2016.12.011

Kim, S. (2017). Who watches Korean TV dramas in Africa? A preliminary study in Ghana. Media, Culture \& Society, 40(2), 296-306. https://doi.org/10.1177/0163443717706069

Kim, S.-H. \& Oh, S.-H. (2020, 8 de abril). Okja, Kingdom, Extracurricular... A verdadeira razão pela qual a Netflix está trabalhando duro na Coreia. Naver. https://news.naver.

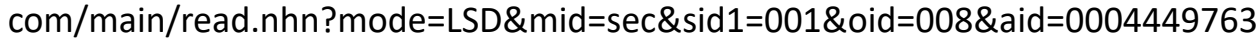

Kim, Y. (2019). The invention of the Mideu: Redefining American television in South Korea. Media, Culture \& Society, 42(1), 109-125. https://doi. org/10.1177/0163443719846611

Kim, Y.-W. (2016, 26 de janeiro). SK Broadband unveils new mobile media platform. The Korea Herald. http://www.koreaherald.com/view.php?ud=20160126001142

KoreaTechToday. (2019, 26 de setembro). Wavve Off To A Rocky Start. https://www. koreatechtoday.com/wavve-off-to-a-rocky-start/

Lee, D. (2004). A local mode of programee adaptation: South Korea in the global television format business. In A. Moran, \& M. Keane (Eds.), Television across Asia: Television industries, programme formats and globalization (pp. 36-53). Routledge Curzon.

Lee, J.-Y. (2016, 7 de janeiro). Netflix launches Korean service. The Korea Herald. http://www.koreaherald.com/view.php?ud=20160107001107

Lee, M. (2020, 9 de setembro). Blackpink, protagonista do primeiro documentário sobre K-pop da Netflix. Newsen. https://entertain.v.daum.net/v/20200909090608245

Lee, Y.-I. \& Lee, H.-Y. (2019, 29 de agosto). Global video streaming giants make fast proliferation in Korea. Pulse. https://pulsenews.co.kr/view. php?year $=2019 \&$ no $=677149$

Lim, S. (2020, 3 de julho). How streaming platform Viu is riding the Korean Wave. The Drum. https://www.thedrum.com/news/2020/07/03/how-streaming-platformviu-riding-the-korean-wave

Lui, J. (2018, 8 de novembro). Netflix announces slate of 17 made-in-Asia shows at content showcase in Singapore. The Straits Times. https://www.straitstimes. com/lifestyle/entertainment/netflix-announces-slate-of-17-made-in-asia-showsat-content-showcase-in 
Mazur, D. (2018). Um Mergulho na Onda Coreana, Nostalgia e Cultura Pop na Série de K-dramas "Reply" [Dissertação de mestrado em Comunicação, Universidade Federal Fluminense].

Mazur, D., Meimaridis, M., \& Albuquerque, A. (2019). Paradigmas televisivos em transição: A adaptação de dramas americanos na Coreia. Revista Latinoamericana de Ciencias de la Comunicación, 17(31), 84-94.

Meimaridis, M., Mazur, D., \& Rios, D. (2020). The streaming wars in the global periphery: a glimpse from Brazil. Series - International Journal of TV Serial Narratives, 6(1), 65-76. https://doi.org/10.6092/issn.2421-454X/10457

Min, W., Jin, D. Y., \& Han, B. (2018). Transcultural fandom of the Korean Wave in Latin America: through the lens of cultural intimacy and affinity space. Media, Culture \& Society, 41(5), 604-619. https://doi.org/10.1177/0163443718799403

Nam, S. (2008). The politics of compressed development in new media: a history of Korean cable television, 1992-2005. Media, Culture \& Society, 30(5), 641-661. https://doi.org/10.1177/0163443708094013

Nye, J. (2004). Soft Power: The Means to Success in World Politics. Public Affairs.

Park, E. (2018). Business strategies of Korean TV players in the age of over-thetop (OTT) video service. International Journal of Communication, 12, 4646-4667.

Riley, C. (2016, 18 de outubro). Netflix admits its plan for China has failed. CNN Business. https://money.cnn.com/2016/10/18/technology/netflix-china/

Rios, S., \& Scarlata, A. (2018). Locating SVOD in Australia and Mexico: Stan and Blim contend with Netflix. Critical Studies in Television, 13(4), 475-490. https://doi. org/10.1177/1749602018798158

Rolli, B. (2020, 22 de janeiro). BlackPink's 'Ddu-Du Ddu-Du' Is The Most-Watched Music Video By A Korean Group On YouTube. Forbes. https://www.forbes.com/ sites/bryanrolli/2019/01/22/blackpinks-ddu-du-ddu-du-is-the-most-watchedmusic-video-by-a-korean-group-on-youtube/\#487cb6b06a25

Seo, H. S. (2018, 15 de outubro). Media industry divided on whether to block or promote Netflix. The Korea Bizwire. http://koreabizwire.com/media-industrydivided-on-whether-to-block-or-promote-netflix/125968

Shim, D. (2006). Hybridity and the rise of Korean popular culture in Asia. Media, Culture \& Society, 28(1), 25-44. https://doi.org/10.1177/0163443706059278

Shim, D. (2008). The growth of Korean cultural industries and the Korean wave. In B. C. Huat, \& K. Iwabuchi (Eds.), East Asian pop culture: Analysing the Korean wave (pp. 15-32). Hong Kong University Press.

Shim, S. (2008). Behind the Korean broadcasting boom. NHK Broadcasting Studies, 6, 205-232.

Shim, W.-H. (2020, 15 de janeiro). Netflix in Korea ordered to change unfair terms of use. The Korea Herald. http://www.koreaherald.com/view.php?ud=20200115000598

Straubhaar, J. D. (1991). Beyond media imperialism: Assymetrical interdependence and cultural proximity. Critical Studies in Media Communication, 8(1), 39-59. https://doi.org/10.1080/15295039109366779

Sung, S.-Y. (2014). K-pop reception and participatory fan culture in Austria. CrossCurrents: East Asian History and Culture Review, 3(1), 56-71. https://doi.org/10.1353/ ACH.2014.0011 
Tai, C. (2020, 5 de agosto). Korean K-dramas and Hallyu films are \#Alive and well, but Bollywood hits rock Bellbottom amid coronavirus slump. South China Morning Post. https://www.scmp.com/week-asia/lifestyle-culture/article/3096022/koreank-dramas-and-hallyu-films-are-alive-and-well

Tse, Y. K. (2020). Black Ships? Locating Netflix in Taiwan and Japan. JCMS: Journal of Cinema and Media Studies, 59(3), 143-148. https://doi.org/10.1353/cj.2020.0036

Urbano, K. (2020). Producões televisivas japonesas e sul-coreanas na Netflix Brasil: apontamentos iniciais. Comunicacao, Midia e Consumo, 17(50), 559-579.

Wee, C. J. W.-L. (2016). East Asian pop culture and the trajectory of Asian consumption. Inter-Asia Cultural Studies, 17(2), 305-315. https://doi.org/10.1080/14649373. 2016.1184428

Yang, S.-J. (2020, 29 de maio). [Digital Simplicity] Netflix faces major regulatory setback in Korea. The Korea Herald. http://www.koreaherald.com/view. php?ud=20200528000846

Yonhap News Agency. (2020a, 14 de abril). Exports of Korean culture products soar 22.4 pct last year. https://en.yna.co.kr/view/AEN20200414009800315

Yonhap News Agency. (2020b, 17 de junho). Local OTT giant Wavve sees drop in active users, Netflix soars: report. The Korea Herald. http://www.koreaherald.com/ view.php?ud=20200617000526 